\section{EVALUATION OF QUANTITATIVE FIT TEST RESULTS FOR FEMALE HEALTH CARE WORKERS IN KOREA}

Hyunwook Kim*, Jennifer Ivy Kim, Hyekyung Seo, Kyangmyung Jang, Kyunghoon Park, Yeji Seong. Department of Preventive Medicine, College of Medicine, The Catholic University of Korea, Seoul, Korea

\subsection{6/oemed-2018-ICOHabstracts.571}

Introduction Risk of infections due to communicable pathogens among health care workers is very high. Though many counter measures have been implemented, respiratory protective devices (RPD) are very common in use for prevention of the inhalation of pathogens. Nevertheless, proper education and training of RPDs are lacking for health care workers. This study is focused on the actual RPDs use and the fit tests so as to establishing effective training programs.

Methods A total of 393 female health care workers were recruited for quantitative fit testing (QNFT), with at least 2 RPDs out of 4 different types of RPDs provided. The U.S. OSHA Fit Test protocol was used to conduct the fit test exercises along with the pass criteria (FF >100). The QNFT results were analysed by division and occupation using STATA.

Results Among participants, all occupations showed relatively high pass percentages except doctors who showed about $40 \%$ of failure with the Folder shaped mask. For almost all divisions, the cup shaped and the cup shaped small size mask showed the highest fail rate, but the folder shaped mask showed lower failure rates. Within the hospital, different failure rates were observed between divisions; emergency room $=13.5 \%, \mathrm{MICU}=3.6 \%, \mathrm{SICU}=8.8 \%, \mathrm{BMTICU}=15.4 \%$, isolation ward $=6.7 \%$, respiratory/infection control division $=3.7 \%$, PICU $=0.0 \%$, and $\mathrm{CCU}=4.3 \%$, respectively. While no association between types of occupation and QNFT result were observed, QNFT results were statistically significantly different between divisions $(\chi 2=17.122, p=0.017)$.

Discussion The results of this study showed that some RPDs perform better in terms of respiratory protection providedaccording to the subjects'facial shapes. And health care professionalsneed formal educationand training for the use of RPDs, regardless of their occupations. Properdonning experiences of RPDs arehighly recommended and annual QNFT are recommended for checking the effectiveness of RPDs.

\section{PRODUCTION AND RELEASE OF CONVECTIVE AND EVAPORATIVE HEAT FLOWS WHEN WEARING RESPIRATORS AND EXERCISING UNDER SIGNIFICANT METABOLIC DEMAND}

${ }^{1} \mathrm{C}-\mathrm{P}$ Chen* ${ }^{2}{ }^{2}$-C Lin, ${ }^{1} \mathrm{H}-\mathrm{C}$ Wei. ${ }^{1}$ Department of Occupational Safety and Health, China Medical University, Taichung, Taiwan; ${ }^{2}$ Department of Public Health, China Medical University, Taichung, Taiwan

\subsection{6/oemed-2018-ICOHabstracts.572}

Introduction When wearing a respirator the metabolic heat accumulated inside the mask affects the comfort of the wearer and thus the efficacy of respirator use. This study evaluated the change in respirator convective and evaporative heat flows occurring in response to the use of respirators of different facepiece design under activities of varying metabolic load.

Methods The study was performed in a climatic chamber with environmental temperature fixed at $25^{\circ} \mathrm{C}$ and relative humidity at $65 \%$. In the experiment, each participant (13 males and
12 females) first exercised under specified activity for $30 \mathrm{~min}$ to thermally adapt and then with a respirator on continued the same activity for another $30 \mathrm{~min}$. The specified activities included sitting in chair, walking on stairs, and jogging, representing exercises of low $\left(70-130 \mathrm{~W} / \mathrm{m}^{2}\right)$, moderate $(130-200$ $\left.\mathrm{W} / \mathrm{m}^{2}\right)$, and very high metabolic rate $\left(>260 \mathrm{~W} / \mathrm{m}^{2}\right)$. Three models of half-mask respirators (two cup-shaped filtering facepieces, including one with and one without exhalation valve, and one elastomeric facepiece with valve) were tested.

Results The increase in the temperature of the respired air when wearing a filtering facepiece was approximately 1.7 to 2.0 folds of when donning the elastomeric facepiece. The change in the convective or evaporative heat flows as a result of wearing either of the filtering facepieces was significantly different among metabolic rates $(p<0.001)$. For both the filtering facepieces, the gradient between the convective and the evaporative heat flows increased with increasing metabolic rate.

Discussion The increase in heat strain resulting from respirator use and metabolic demand heightened the requirement of heat dissipation, particularly if the wearers worked strenuously in hot environment. The elastomeric facepiece with an exhalation valve relieved the hot-and-humid air inside the mask more effectively than the filtering facepieces did in this study, lowering thermal discomfort and potential heat stress.

\section{DUST CONTROL MEASURES IN THE REDUCTION OF SILICA EXPOSURE ON SURFACE MINES}

${ }^{1}$ Louwna Pretorius*, ${ }^{2}$ B Strauss. ${ }^{1}$ Corobrik Pty (Ltd) Edenvale, South Africa; ${ }^{2} \mathrm{NOHS}$ Consultants- Roodepoort- South Africa

\subsection{6/oemed-2018-ICOHabstracts.573}

Introduction There are several types of surface mining, but the three most common are open pit, strip mining and quarrying. Open cast mining activities produce dust. In open cast mining the process of accessing the ore body involves the removal of the natural land surface, using mobile excavation equipment such as bull dozers, front end loaders, and haulage trucks.

Recent studies have found that silica dust confers an increased risk for Tuberculosis, and that the risk persists even after dust exposure ends. The interaction between inadequate silica dust control, a high burden of HIV/Aids and Tuberculosis, present major challenges to occupational hygiene control measures in silica dust suppression as well as medical surveillance monitoring programmes.

Methods Stratified random sampling from five homogenous exposure groups $(n=30)$ in two settings was used in a descriptive correlational research design to compare the personal gravimetric sampling results of silica dust and the implementation of dust suppression methods on employees.

Results The results indicated a positive correlation between dust suppression and a reduction in employee 's personal exposure.

Discussion A primary prevention approach entails controlling the dust at source so as to reduce the employee exposure through the introduction of dust control measures, and appropriate technologies i.e. process enclosure, and wet techniques. It includes the enclosing/installation of air conditioning systems on mobile equipment, and closing of cab windows in driven equipment. Haul road dust control includes the constant 